\title{
Los bienes de interés cultural y su naturaleza de bienes públicos ${ }^{1}$
}

Juan Manuel Vargas-Ayala ${ }^{2}$

\section{RESUMEN}

El presente artículo plantea un debate trascendental en el tema de los bienes de interés cultural como bienes públicos, discusión que hasta el momento no ha sido objeto de una atención considerable por parte de la doctrina nacional en derecho administrativo. A partir de pronunciamientos jurisprudenciales, este trabajo busca precisamente interrogarse sobre el carácter de inalienables y sobre la vocación final que tienen este tipo de bienes de ser adquiridos por el Estado, mutando su naturaleza a la de bienes públicos.

Palabras clave: Bienes de interés cultural, Bienes públicos, Bienes del Estado, Bienes inalienables.

\section{Cultural Interest Goods as Public Goods}

\section{ABSTRACT}

This paper presents the debate regarding the nature of goods of cultural interest as public goods, discussion until now overlooked by the legal doctrine in Administrative Law. Through the exam of judicial decisions, it seeks to

1 Discusión originalmente abordada durante el $1 .{ }^{\text {er }}$ Seminario Internacional "Bienes Públicos", organizado por el Departamento de Derecho Administrativo de la Universidad Externado de Colombia, Bogotá, junio de 2016.

2 Abogado de la Universidad Externado de Colombia, Bogotá, Colombia. Jefe de la Oficina Jurídica del Ministerio de Cultura, Bogotá, Colombia. Correo-e: jumavargas@hotmail.com Fecha de recepción: 10 de octubre de 2016. Fecha de modificación: 30 de septiembre de 2016. Fecha de aceptación: 25 de noviembre de 2016. Para citar el artículo: Vargas-Ayala, J. M. "Los bienes de interés cultural y su naturaleza de bienes públicos", Revista digital de Derecho Administrativo, n. ${ }^{\circ}$ 17, primer semestre, Universidad Externado de Colombia, 2017, pp. 293-308. DOI: http://dx.doi.org/10.18601/21452946.n17.14 
question their inalienable character, and their aptitude to be acquired by the State, case in which they shift their nature into public goods.

Keywords: Goods of Cultural Interest, Public Goods, State owned Goods, Inalienable Goods.

\section{INTRODUCCIÓN}

Intentaremos abordar en este trabajo un asunto de inmensa trascendencia dentro del ámbito de los bienes de interés cultural y su connotación o no como bienes públicos. Es este apenas el inicio de un asunto que deberá ser abordado desde las perspectivas multidisciplinarias que el tema amerita y que no se pretende agotar aquí.

\section{MARCO NORMATIVO DE LOS BIENES DE INTERÉS CULTURAL}

Sea lo primero hacer una breve explicación del contexto normativo en el cual esta problemática se desarrolla.

Encontramos en primer lugar los artículos 63 y 72 de la Constitución Política colombiana. El artículo 63 dispone: "Los bienes de uso público, los parques naturales, las tierras comunales de grupos étnicos, las tierras de resguardo, el patrimonio arqueológico de la Nación y los demás bienes que determine la ley, son inalienables, imprescriptibles e inembargables".

Esta clara disposición tiene su complemento en el artículo 72 de Carta que preceptúa:

El patrimonio cultural de la Nación está bajo la protección del Estado. El patrimonio arqueológico y otros bienes culturales que conforman la identidad nacional, pertenecen a la Nación y son inalienables, inembargables e imprescriptibles. La ley establecerá los mecanismos para readquirirlos cuando se encuentren en manos de particulares y reglamentará los derechos especiales que pudieran tener los grupos étnicos asentados en territorios de riqueza arqueológica.

Como bien lo dispone el citado artículo 63, la Constitución les confiere el carácter de inalienabilidad, inembargabilidad e imprescriptibilidad, inherentes a su condición de bienes que podríamos llamar especiales, dado que están sometidos a una especial carga pública, como lo ha reconocido la Corte Constitucional.

Esta especial carga puede derivarse del hecho de que su afectación al servicio de la sociedad los hacen ostentar estas características particularísimas y que no son propias sino de unos pocos tipos de bienes. 
Como lo expresa el artículo 63, la Constitución defiere al Legislador la determinación acerca de cuáles de aquellos bienes diferentes a los ya enunciados (bienes de uso público, los parques naturales, las tierras comunales de grupos étnicos, las tierras de resguardo, el patrimonio arqueológico de la Nación) serán sometidos a este régimen especial de inalienabilidad, inembargabilidad e imprescriptibilidad, dentro de la amplia libertad de configuración normativa que la misma Constitución y la doctrina otorgan al legislador.

Luego el artículo 72 reafirma este concepto al decir que los bienes de patrimonio arqueológico y "otros bienes que conforman la identidad nacional" pertenecen a la Nación, y confirma su particular carácter de inalienabilidad, inembargabilidad e imprescriptibilidad.

A continuación plantea que sobre dichos bienes "la ley establecerá los mecanismos para readquirirlos cuando se encuentren en manos de particulares y reglamentará los derechos especiales que pudieran tener los grupos étnicos asentados en territorios de riqueza arqueológica".

Esto conduce a concluir que los bienes de carácter arqueológico son indudablemente propiedad de la Nación y que con relación a los demás bienes que conforman la identidad nacional adquirirán este carácter en el momento en que el legislador, mediante ley, y en desarrollo de la libertad de configuración que le asiste al Congreso, se los confiera.

Bajo estos parámetros el legislador colombiano desarrolló estas normas constitucionales a través de la Ley 397 de 1997 en su artículo 6. ${ }^{\circ}$, modificado por el artículo 3. ${ }^{\circ}$ de la Ley 1185 de 2008, el cual dispone:

Artículo 6. ${ }^{\circ}$ Patrimonio arqueológico. El patrimonio arqueológico comprende aquellos vestigios producto de la actividad humana y aquellos restos orgánicos e inorgánicos que, mediante los métodos y técnicas propios de la arqueología y otras ciencias afines, permiten reconstruir y dar a conocer los orígenes y las trayectorias socioculturales pasadas y garantizan su conservación y restauración. Para la preservación de los bienes integrantes del patrimonio paleontológico se aplicarán los mismos instrumentos establecidos para el patrimonio arqueológico.

De conformidad con los artículos 63 y 72 de la Constitución Política, los bienes del patrimonio arqueológico pertenecen a la Nación y son inalienables, imprescriptibles e inembargables.

El Instituto Colombiano de Antropología e Historia, ICANH, podrá autorizar a las personas naturales o jurídicas para ejercer la tenencia de los bienes del patrimonio arqueológico, siempre que estas cumplan con las obligaciones de registro, manejo y seguridad de dichos bienes que determine el Instituto.

Los particulares tenedores de bienes arqueológicos deben registrarlos. La falta de registro en un término máximo de 5 años a partir de la vigencia de esta ley 
constituye causal de decomiso de conformidad con el Decreto 833 de 2002, sin perjuicio de las demás causales allí establecidas.

El ICANH es la institución competente en el territorio nacional respecto del manejo del patrimonio arqueológico. Este podrá declarar áreas protegidas en las que existan bienes de los descritos en el inciso $1 .^{\circ}$ de este artículo y aprobará el respectivo Plan de Manejo Arqueológico, declaratoria que no afecta la propiedad del suelo...

Efectuada ya la precisión sobre el régimen aplicable a los bienes del patrimonio arqueológico, es menester ahora ahondar en el régimen de aquellos otros bienes que, a las voces de los artículos constitucionales ya citados, tendrían este régimen especialísimo.

Para esto la Ley 397 de 1997 (Ley General de Cultura) establece en su artículo $10{ }^{\circ}$, con la modificación introducida por el artículo $6 .^{\circ}$ de la Ley 1185 de 2008: "Inembargabilidad, imprescriptibilidad, e inelianabilidad. Los bienes de interés cultural de propiedad de entidades públicas, son inembargables, imprescriptibles e inalienables".

Establece entonces aquí el legislador la premisa fundamental para la categorización como bienes inalienables, inembargables e imprescriptibles, en desarrollo, como ya lo mencionamos, de su libertad de configuración: solo tendrán este carácter aquellos bienes de interés cultural que sean de propiedad de entidades públicas.

Esto conlleva también el reconocimiento de, como lo plantea la propia Constitución, la existencia de propiedad privada sobre todos aquellos bienes de interés cultural que no sean de propiedad de una entidad pública. Y desarrolla lo anterior en el siguiente parágrafo del mismo artículo $10 .^{\circ}$ :

Parágrafo 1. El Ministerio de Cultura autorizará, en casos excepcionales, la enajenación o el préstamo de bienes de interés cultural del ámbito nacional entre entidades públicas. Las alcaldías, gobernaciones y autoridades de los territorios indígenas y de las comunidades negras de que trata la Ley 70 de 1993, serán las encargadas de dar aplicación a lo previsto en este parágrafo respecto de los bienes de interés cultural declarados por ellas.

Las autoridades señaladas en este parágrafo podrán autorizar a las entidades públicas propietarias de bienes de interés cultural para darlos en comodato a entidades privadas sin ánimo de lucro de reconocida idoneidad, hasta por el término de cinco (5) años prorrogables con sujeción a lo previsto en el artículo 355 de la Constitución Política, celebrar convenios interadministrativos y de asociación en la forma prevista en los artículos 95 y 96 de la Ley 489 de 1998 o en las normas que los modifiquen o sustituyan, y en general, celebrar cualquier tipo de contrato, incluido el de concesión, que implique la entrega de dichos bienes a particulares, siempre que cualquiera de las modalidades que se utilice se dirija a proveer y garantizar lo necesario para la protección, recuperación, conservación, sostenibilidad 
y divulgación de los mismos, sin afectar su inalienabilidad, imprescriptibilidad e inembargabilidad.

Tenemos entonces un claro marco normativo planteado por la Constitución Política y las leyes 397 de 1997 y 1185 de 2008. Este marco permite que particulares tengan el pleno dominio sobre bienes de interés cultural que no sean propiedad de entidades públicas.

Estos particulares para el ejercicio de sus derechos sobre dichos bienes tendrán, adicionalmente a las limitaciones que tiene cualquier ciudadano en relación con un bien cualquiera, consignadas en el ordenamiento urbano, que estar sometidos al régimen de protección del patrimonio cultural consagrado en las leyes ya citadas varias veces, y sus decretos reglamentarios (en este caso el Decreto Único 1080 de 2015), régimen que establece restricciones a la libre disposición de dichos bienes, tales como la necesaria autorización previa de la autoridad que realizó la declaratoria, para cualquier intervención que se pretenda hacer sobre el inmueble que tenga esta declaratoria.

\section{ANTECEDENTES JURISPRUDENCIALES SOBRE ESTOS TEMAS}

La Corte Constitucional se ha ocupado de estos temas en diversas oportunidades. La misma sentencia C-082 de 2014 que analizaremos hace un breve recuento de pronunciamientos anteriores.

Respecto de los múltiples pronunciamientos sobre estos temas por parte de la Corte Constitucional, en los cuales no me voy a detener, intentaré recoger el resumen que la misma Corte hace en la sentencia ya citada, indicando que aparte de la gran clasificación de bienes fiscales y bienes de uso público, se reconocen otro tipo de bienes, los cuales, "por sus condiciones y características particulares, representan un valor especial para el Estado y la sociedad. Con respecto a algunos de dichos bienes, es la propia Constitución la que se ocupa de ellos, disponiendo su pertenencia a la Nación" ${ }^{\prime \prime}$. Y continúa la Corte en la misma sentencia:

Tal es el caso, por ejemplo, de los bienes culturales, cuya categoría es reconocida directamente por el artículo 72 de la Carta, el cual establece que "[e]l patrimonio ardueológico y otros bienes culturales que conforman la identidad nacional, pertenecen a la $\mathrm{Na}$ ción y son inalienables, inembargables e imprescriptibles". Como se explicará en detalle en el siguiente apartado, hacen parte de los bienes culturales de la Nación, entre otros, los bienes muebles e inmuebles, de naturaleza pública o privada, a los que se les atribuye un especial interés, sea éste histórico, artístico, científico, estético 
o simbólico, en ámbitos tales como el arquitectónico, urbanístico, arqueológico, museológico o antropológico.

Esta categoría de bienes, sobre los cuales el Estado debe tener una vocación de dominio y pertenencia, además de tener la condición de inalienables, inembargables e imprescriptibles, son objeto de una protección especial por parte del Estado, conforme a los parámetros y reglas que define la ley ${ }^{4}$.

Luego de hacer un recorrido por la Constitución de 1886, la cual no consagraba de manera expresa la protección al patrimonio cultural, manifiesta la Corte cómo la Constitución de 1991:

Le dedica un amplio espacio a la cultura. Con un propósito claro de defensa del patrimonio cultural en sus distintas manifestaciones, y como expresión de la diversidad de las comunidades, de la riqueza humana y social de los pueblos y como instrumento para construir sociedades organizadas, la cultura es reconocida por la actual Carta Política como un pilar fundamental del Estado y como valor, principio, derecho y deber que requiere especial protección, fomento y divulgación por parte de las autoridades públicas e incluso por los particulares ${ }^{5}$.

A este respecto, la Corte ha señalado que es amplio el conjunto de disposiciones constitucionales que protegen la cultura, su diversidad y el patrimonio cultural como valores esenciales de la Nación, lo que le ha permitido a dicho bloque normativo recibir el calificativo de "Constitución Cultural".

Y concluye la Corte citando la sentencia C-742 de 2006:

"La protección del patrimonio cultural de la Nación tiene especial relevancia en la Constitución, en tanto que éste constituye un signo o una expresión de la cultura humana, de un tiempo, de circunstancias o modalidades de vida que se reflejan en el territorio, pero que desbordan sus límites y dimensiones" ${ }^{\prime \prime}$, para lo cual, "la salvaguarda estatal del patrimonio cultural de la Nación tiene sentido en cuanto, después de un proceso de formación, transformación y apropiación, expresa la identidad de un grupo social en un momento histórico"7.

Luego de reconocer el deber en cabeza del Estado y de todos los ciudadanos sobre el cuidado y protección del patrimonio cultural, la Corte, citando la sentencia C-366 de 2000, plantea:

$4 \quad$ Ibíd

5 ibíd.

6 Corte Constitucional, sentencia C-742 de 2006.

7 Ibíd. 
La declaración de un bien como parte integrante del patrimonio cultural de la $\mathrm{Na}$ ción lleva consigo una serie de restricciones al derecho de propiedad, e imposición de cargas para los propietarios de éstos que, en concepto de esta Corporación, se relacionan con su disponibilidad y ello, incluye, por supuesto, el uso o destinación que ha de darse al bien para efectos de la conservación y protección ${ }^{8}$.

\section{LA POSICIÓN DE LA CORTE CONSTITUCIONAL EN LA SENTENCIA C-082 DE 2014}

La Corte Constitucional hizo el último pronunciamiento sobre estos tópicos por medio de la sentencia C-082 de 2014, ya abundantemente citada en este escrito. En dicha sentencia, por vía de la acción pública de inconstitucionalidad, se pretendía declarar la inexequibilidad del artículo 116 de la Ley 1617 de 2013, también denominada Ley de Distritos. Dicho artículo dispone:

Artículo 116. Autorízase a la Nación-Ministerio de Cultura, para entregar gratuitamente a la Alcaldía de Buenaventura el inmueble donde funcionó la Estación de los Ferrocarriles Nacionales, ubicado en el distrito, sin más trámites y requisitos que los estrictamente necesarios para este tipo de operaciones.

Parágrafo $1 .^{\circ}$ El inmueble cedido a la Alcaldía de Buenaventura seguirá conservando su importancia como patrimonio histórico y su uso estará destinado a que funcione allí el Centro Histórico del municipio de Buenaventura y el Centro de Convenciones, Información y Documentación del Pacífico.

Se planteaba por parte del actor la posible vulneración de los artículos 63 y 72 de la Carta, los cuales disponen la inalienabilidad de estos bienes, pertenecientes en este caso a la Nación a través del Ministerio de Cultura, ya que se consideraba que el transferir el bien en cuestión a otra orbita territorial, en este caso el Distrito de Buenaventura, podría configurar una vulneración de dichas normas constitucionales.

La Corte Constitucional hace un análisis de la problemática jurídica planteada, y en desarrollo de la participación de las diversas entidades, ciudadanos e instituciones públicas, cabe resaltar los argumentos planteados dentro del expediente de la acción de inconstitucionalidad.

1. El Procurador General de la Nación plantea la exequibilidad de la norma (art. 116) con base en lo dispuesto en los artículo 63 y 72 de la Carta y, en especial, en lo consignado en el artículo 10 de la Ley 397 de 1997. Eso sí, advierte el Ministerio Público que el bien con su transferencia no pierde su condición de bien nacional y de patrimonio cultural de la Nación, y por lo 
tanto "cualquier disposición posterior en materia de derecho de propiedad pública que le asiste (uso, goce o disposición), debe ser decidida directamente por la misma ley y no por normas del orden distrital, porque así lo disponen los artículos 63 y 72 de la Carta Política".

En consecuencia, solicita a la Corte Constitucional que declare la exequibilidad del artículo 116 de la Ley 1617 de 2013, haciendo la precisión de que las decisiones que se adopten con posterioridad en relación con la propiedad pública del inmueble deben ser adoptadas directamente por el legislador ${ }^{10}$.

2. De igual manera ha de mencionarse que el concepto presentado por la Academia Colombiana de Jurisprudencia dentro del proceso coincide en los criterios del actor, planteando en su concepto, según el resumen que del mismo hace la sentencia de la Corte:

En cuanto al cargo formulado contra el artículo 116 de la Ley 1617 de 2013, el interviniente empieza por realizar un análisis de las principales características de los bienes de uso público y de aquellos que hacen parte del patrimonio cultural de la Nación. A partir de esas reflexiones, afirma que la Estación de Ferrocarriles Nacionales ubicada en la ciudad de Buenaventura, efectivamente hace parte de ese patrimonio y que, por tanto, tiene la condición de ser inembargable, inalienable e imprescriptible.

Así, si bien es posible realizar transferencias de bienes entre entidades públicas, siempre que el Congreso lo autorice ${ }^{11}$, cuando se trata de bienes que hacen parte del patrimonio cultural de la Nación hay una expresa prohibición en la Carta Política, por lo que ellos no pueden ser transferidos a ningún título.

Por tal razón, a juicio del interviniente el artículo 116 de la Ley 1617 de 2013 debe ser declarado inexequible, por ser contrario al principio de inalienabilidad de los bienes que conforman la identidad nacional ${ }^{12}$.

La Corte propone analizar tres aspectos a fin de poder dilucidar el problema jurídico planteado:

1. En primer lugar, la naturaleza pública de los bienes culturales;

2. Luego, el régimen de protección del patrimonio cultural de la Nación, y

3. Por último, los alcances y límites del atributo de inalienabilidad que pesa sobre los bienes que hacen parte del patrimonio cultural de la Nación.

9 Corte Constitucional, sentencia C-082 de 2014.

10 Ibíd.

11 Consejo de Estado, Sala de Consulta y Servicio Civil, concepto del 15 de diciembre de 2004.

12 Ibíd. 
Entra entonces la Corte a estudiar estos aspectos en la sentencia C-082 de 2014, y luego de hacer una transcripción de las normas de la Ley General de Cultura que regulan la materia, concluye:

Del análisis sistemático de las disposiciones constitucionales y legales a que se ha hecho referencia, y dentro del propósito de orientar la decisión por tomar en esta causa, se colige que el patrimonio cultural de la Nación se encuentra bajo la protección del Estado (C.P. art. 72), y el mismo está constituido por todos los bienes de naturaleza pública o privada a que hace referencia expresa el artículo $4{ }^{\circ}$ de la Ley 397 de 1997, entre los que se cuentan los bienes materiales muebles e inmuebles a los que se les atribuye, entre otros, especial interés histórico, artístico, científico, estético o simbólico en ámbitos como el plástico, arquitectónico, urbano, arqueológico, lingüístico, sonoro, musical, audiovisual, fílmico, testimonial, documental, literario, bibliográfico, museológico o antropológico.

En la medida en que por expresa disposición constitucional los bienes inmuebles declarados como de interés cultural "pertenecen a la Nación", le corresponde al Estado, en el caso de que los mismos sean de naturaleza pública, el deber de mantener su dominio, para lo cual es la propia Carta Política las que les reconoce la condición de "inalienables, inembargables e imprescriptibles" (C.P. art. 72). Asimismo, en caso de que tales bienes se encuentren en manos de particulares, debe el legislador establecer los mecanismos necesarios para su readquisición por parte del Estado (C.P. art. 72), quedando en todo caso sometidos al régimen especial previsto en la Ley 397 de 1997.

De igual manera, dentro de los bienes que hacen parte del patrimonio cultural de la Nación, la Constitución y la ley diferencian (i) los bienes que integran el patrimonio arqueológico de la Nación (C.P. arts. 63 y 72), y (ii) los bienes culturales que conforman la identidad nacional (C.P. art. 72). Con respecto a los dos grupos de bienes, no se requiere que los mismos sean declarados como tales para que tengan el carácter de inalienables, inembargables e imprescriptibles. Igualmente, las dos categorías de bienes pueden tener la condición de "bienes de interés cultural" de los ámbitos nacional, departamental, distrital, municipal, o de los territorios indígenas o de las comunidades negras y, en consecuencia, quedan sujetos al régimen especial previsto en la Ley 397 de $1997^{[13]}$.

Obsérvese cómo desde ya la Corte empieza a asimilar, en nuestro criterio de manera errada, que todos los bienes de interés cultural declarados están amparados por el concepto de inalienabilidad, inembargabilidad e imprescriptibilidad consagrado en las normas constitucionales.

La norma es clara en los artículos 63 y 72, en el sentido de que será el legislador quien determinará que aquellos bienes que han sido declarados como 
de interés cultural tendrán este carácter. Y en desarrollo de dicho precepto las leyes 397 de 1997 y 1185 de 2008 los han circunscrito a aquellos bienes que estén en cabeza de entidades públicas.

Continúa más adelante la Corte:

No obstante, considera la Corte que el significado que en términos generales se reconoce a la prohibición de inalienabilidad, debe entenderse comprendida en el contexto de la finalidad que persigue el régimen constitucional de protección del patrimonio cultural y arqueológico de la Nación, cual es la preservación, recuperación y conservación de los bienes que lo integran. Si ello es así, la condición de inalienabilidad a que alude el artículo 72 Superior, respecto de los bienes culturales de propiedad pública, lo que persigue en realidad es su exclusión del tráfico jurídico propio del derecho privado y, por esa vía, impedir que tales bienes pasen a manos de particulares o se mantengan en ellas, dentro del propósito de garantizar el estatus de protección estatal que su condición les reconoce ${ }^{14}$.

Y prosigue luego:

Y es que, según está previsto en el artículo $4 .^{\circ}$ de la citada Ley 397 de 1997, desde el punto de vista de la propiedad, los bienes del patrimonio cultural de la Nación pueden pertenecer, según el caso, a la Nación, a entidades públicas de cualquier orden o a personas naturales o jurídicas de derecho privado. A partir de dicha clasificación, el mandato constitucional de inalienabilidad, se extiende sobre todos los bienes públicos que hacen parte del patrimonio cultural de la Nación, independientemente de la autoridad a la que pertenezcan, sea ésta del nivel central o territorial, en el sentido de que ninguno de ellos puede ser enajenado, pero siempre dentro del propósito de impedir que tales bienes puedan ser objeto de actos jurídicos que impliquen tradición o pérdida de la finalidad del bien a favor de particulares. De ese modo, la inalienabilidad a que hace referencia expresa el artículo 72 de la Carta, tiene un alcance relativo y no absoluto, en cuanto se dirige a impedir la transferencia de los bienes que forman parte del patrimonio cultural a los particulares, siendo posible que el Estado pueda disponer de tales bienes dentro del ámbito de la propiedad estatal a través de su reasignación entre entidades públicas.

La jurisprudencia de esta Corporación ha señalado, que la protección al patrimonio cultural y arqueológico de la Nación que prohíja la Constitución, no se agota con el hecho de que ciertos bienes sean declarados como parte de dicho patrimonio. La misma se extiende también, al propósito de lograr que los bienes a los que se les ha reconocido alguna de tales condiciones, sean recuperados y permanezcan en manos del Estado. A este último cometido es que apunta la prohibición de inalienabilidad prevista en el precitado artículo 72 Superior, pues, como se mencionó, a través de ella se garantiza que los bienes públicos que hacen parte del patrimonio 
cultural de la Nación no puedan ser negociados o comercializados con particulares y se mantengan siempre en la órbita estatal o pública ${ }^{15}$.

\section{Para resaltar más adelante la Corte:}

Pues bien, una lectura sistemática de las anteriores premisas, vistas a luz del propósito perseguido por la disposición superior a la que se integran, no deja duda acerca de su objetivo, cual es el comprometer a todas las autoridades públicas en la defensa y protección del patrimonio cultural, procurando a su vez que dichos bienes se encuentren bajo el dominio público y no salgan del mismo, lo cual se logra, como se ha dicho, excluyéndolos del comercio y del patrimonio privado, conforme a los atributos de inalienabilidad, inembargabilidad e imprescriptibilidad que aquellos detentan ${ }^{16}$.

Para sustentar su tesis la Corte acude a los debates adelantados en la Comisión Primera de la Asamblea Nacional Constituyente, citando este aparte:

"... el patrimonio cultural normalmente depredado en Colombia, sin ninguna clase de contemplaciones, con la total desidia del Gobierno, se han destruido monumentos maravillosos de épocas coloniales [...] el patrimonio artístico de las iglesias que contienen obras valiosas artísticas de la colonia, de la manera más normal son saqueadas, son robadas, los cuadros desaparecen y no hay nadie que responda.

"... los Gobiernos tienen que disponer de los mecanismos necesarios para la protección de este patrimonio, no podemos seguir permitiendo que se siga comercializando sin ninguna protección. Es importante que tomemos consciencia del valor del patrimonio.

$[\ldots]$

"... lo que se trata de buscar es que pertenezcan a la Nación y que no estén en manos de particulares [...], eso es lo que se trata de buscar, [...] [la ley] establecerá también los mecanismos para que el Gobierno pueda readquirir los bienes arqueológicos que se encuentren en manos de particulares [...

"... el Estado deberá promover la readquisición de aquellos bienes del patrimonio arqueológico de la Nación que por alguna circunstancia está en manos de

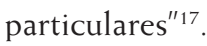

15 Ibíd

16 Ibíd.

17 Citado de la sentencia de la Corte Constitucional, C-082 de 2014, de la obra Corte Constitucional, Constitución Política de Colombia, Antecedentes artículo 71 y 72, Asamblea Nacional Constituyente, p. 34. 
Como se ve claramente, en Comisión se planteó el debate circunscribiendo el alcance de la norma debatida a los bienes arqueológicos, respecto de los cuales ya hemos planteado que no existe duda alguna sobre su pertenencia a la Nación.

Posteriormente la Corte cita lo debatido en la Plenaria donde se propuso que se ampliara también este carácter a todo el patrimonio cultural:

"En relación con el patrimonio cultural me permito sugerir que no se refiera tanto al patrimonio arqueológico, sino que se extienda también en la parte que dice: que la ley extenderá también sus mecanismos para que el Gobierno pueda readquirir los bienes, no sólo los arqueológicos sino los bienes del patrimonio cultural de la Nación y que se encuentran en manos de particulares, y en el exterior para evitar su salida del país y para su conservación"18.

Para reafirmar su criterio, la Corte cita la sentencia C-474 de 2003 en la cual, al examinar unos cargos de inconstitucionalidad contra el artículo 9. ${ }^{\circ}$ de la Ley General de Cultura, el cual establecía, para el caso del patrimonio cultural sumergido, la posibilidad de pagar al denunciante con un valor de las especies náufragas que se encontraran en las coordenadas denunciadas, concluía que debía darse una exequibilidad condicionada a que no podría pagarse sino compensarse con un valor equivalente al de las especies náufragas.

Este tema, sea dicho de paso, ha sido ampliamente superado con la expedición de la Ley 1675 de 2013, que ya definió, siguiendo los lineamientos de la misma sentencia citada por la Corte, que todo lo sumergido hace parte del contexto arqueológico, pero que solamente aquello a lo que se pueda atribuir un valor cultural será considerado patrimonio cultural, acogiéndose para ello a los cinco criterios definidos en dicha ley.

La redacción final de la norma constitucional (art. 72) correspondió a los criterios planteados en la Comisión Primera de la Asamblea Constituyente, circunscrita entonces a los bienes arqueológicos y aquellos que la ley establezca que deberán tener este carácter.

Por eso concluye la Corte en la sentencia C-082 de 2014:

En ese sentido, es claro que la lectura que surge de artículo 72 Superior, en cuanto a la regla que le $[\mathrm{s}]$ reconoce a los bienes que integran el patrimonio arqueológico y cultural de la Nación, el carácter de inalienables, inembargables e imprescriptibles, es la de que a través de tales atributos se buscan impedir que los referidos bienes puedan circular en la órbita del comercio y del patrimonio privado y puedan permanecer en cabeza de los particulares. Tal interpretación es concordante con el mandato previsto en la propia norma, mediante el cual se faculta a la ley para establecer los mecanismos que permitan readquirir los bienes que integran el 
patrimonio arqueológico y cultural de la Nación cuando se encuentren en manos de particulares ${ }^{19}$.

\section{EL RIESGO PARA EL PATRIMONIO CULTURAL}

Están entonces en juego dos conceptos que deberían diferenciarse claramente y que infortunadamente la Corte no distingue: el régimen de pertenencia a la Nación aplica en principio solamente al patrimonio arqueológico y la ley lo extenderá a aquellos bienes de interés cultural que considere deben quedar cobijados. En ese orden de ideas, la ley lo extendió exclusivamente a aquellos bienes que teniendo declaratoria como bienes de interés cultural sean propiedad de una entidad pública. La Corte a su vez lo extiende a todos los bienes de interés cultural, al establecer una nueva categoría como bienes que tienen vocación de convertirse en bienes públicos. Esta nueva categoría, la cual, insistimos, no interpreta cabalmente las normas constitucionales en estudio, suscita más dudas que certezas.

Sea lo primero manifestar que el propósito de la interpretación de la Corte es la salvaguardia y protección del patrimonio. Bajo estos parámetros planteados por la Corte, surgen los problemas que a diario se viven en la protección de dichos bienes, y que se agravan de manera significativa con la interpretación aquí analizada.

La protección del patrimonio cultural implica la interacción entre varias áreas del conocimiento, empezando por supuesto, por las áreas científicas involucradas y por el derecho. Como sucede con los temas ambientales, la protección debe darse desde una perspectiva multidisiciplinaria que permita la cabal comprensión del problema y la mejor forma de solucionarlo. No es difícil entrever las dificultades a las cuales se ve expuesto un juez al momento de tomar decisiones, cuando sólo se apoya en la literalidad de las normas sin atender los criterios científicos que están íntimamente relacionados con la materia. Por eso vemos con indeseable frecuencia fallos judiciales en que los jueces, dentro de la mayor buena fe y con el deseo de acertar, adoptan decisiones pensando en la debida protección del patrimonio cultural y/o el medio ambiente, y terminan en muchos casos exponiendo a dichos bienes jurídicos a riesgos mayores de los que se pretende salvaguardar.

Los aspectos prácticos son extensos, pero vamos aquí, para efectos de nuestro análisis, traer a colación solamente algunos de ellos:

1. Habría que analizar, por ejemplo, el tratamiento se debería dar a todos aquellos bienes que están en cabeza de la Iglesia Católica y que hacen parte muy importante y significativa de nuestra historia colonial. 
Según la interpretación de la Corte, ċlos templos y demás construcciones de la Iglesia Católica deberían ser entonces adquiridos por el Estado, con el referido propósito de "protegerlos"?

¿Es una forma efectiva de protección de dichos bienes sustraerlos de la órbita de su titular del dominio, más aun si tenemos en cuenta que dichos bienes fueron construidos y han sido utilizados en su mayoría para la celebración de ritos religiosos, con un indudable contenido cultural también?

¿Habría asimismo que proceder a readquirir los bienes de otras congregaciones religiosas, sobre las cuales también hay una declaratoria?

¿Qué pasaría con la libertad de cultos? ¿No podría considerarse esto una afrenta abierta a la libertad de cultos?

El artículo $4 .^{\circ}$ de la Ley 397 de 1997, cuando establece cómo se integra el patrimonio cultural, reconoce en su parágrafo el derecho que les asiste a las confesiones religiosas a mantener la propiedad de sus bienes:

Artículo $4{ }^{\circ}$ Integración del patrimonio cultural de la Nación. El patrimonio cultural de la Nación está constituido por todos los bienes materiales, las manifestaciones inmateriales, los productos y las representaciones de la cultura que son expresión de la nacionalidad colombiana, tales como la lengua castellana, las lenguas y dialectos de las comunidades indígenas, negras y creoles, la tradición, el conocimiento ancestral, el paisaje cultural, las costumbres y los hábitos, así como los bienes materiales de naturaleza mueble e inmueble a los que se les atribuye, entre otros, especial interés histórico, artístico, científico, estético o simbólico en ámbitos como el plástico, arquitectónico, urbano, arqueológico, lingüístico, sonoro, musical, audiovisual, fílmico, testimonial, documental, literario, bibliográfico, museológico o antropológico.

$[\ldots]$

Parágrafo. Se reconoce el derecho de las iglesias y confesiones religiosas de ser propietarias del patrimonio cultural que hayan creado, adquirido con sus recursos o que estén bajo su legítima posesión. Igualmente, se protegen la naturaleza y finalidad religiosa de dichos bienes, las cuales no podrán ser obstaculizadas ni impedidas por su valor cultural.

Al tenor del artículo 15 de la Ley 133 de 1994, el Estado a través del Ministerio de Cultura, celebrará con las correspondientes iglesias y confesiones religiosas, convenios para la protección de este patrimonio y para la efectiva aplicación del Régimen Especial de Protección cuando hubieran sido declarados como de interés cultural, incluyendo las restricciones a su enajenación y exportación y las medidas para su inventario, conservación, restauración, estudio y exposición.

Según la tesis que venimos analizando, en aras de su protección las congregaciones religiosas se verían obligadas a vender dichos bienes al Estado, quien 
entonces seguramente procedería a celebrar convenios con ellas para la continuación la utilización de los mismos. ¿Podría tener el Estado la facultad de abstenerse de entregar estos bienes a sus anteriores propietarios, a título de comodatarios o meros tenedores? Es que no puede perderse de vista que dichos bienes fueron construidos con el propósito de celebrar ritos y ceremonias de una congregación religiosa, y resulta realmente exótico que el Estado se vea en la necesidad de adquirirlos. ¿No ofrecen mejor protección muchas veces las mismas comunidades religiosas que cuidan de esos bienes de su propiedad?

¿De qué manera podría el Estado conseguir recursos en la "explotación comercial" de dichos bienes, para lograr su sostenibilidad?

Muchos podrán sostener así que, bajo el prisma de esta interpretación de la Corte, este parágrafo del artículo $4 .^{\circ}$ de la Ley 397 de 1997 sería inconstitucional al permitir la propiedad de dichos bienes a entidades distintas al propio Estado.

Si miramos otros ámbitos del patrimonio cultural podríamos hacernos otra serie de preguntas sobre otro tipo de bienes.

2. El Ministerio de Cultura declaró como bien patrimonial el Paisaje Cultural Cafetero, el cual fue declarado también Patrimonio de la Humanidad por la UNESCO. Esta declaratoria reconoce y protege un especial interactuar de una comunidad con un territorio para la explotación comercial de este.

¿Será que, en aras de atender el sentido de la protección del patrimonio que propugna la interpretación de la Corte, deberá el Estado proceder a adquirir 141.120 hectáreas de terrenos objeto de la declaratoria? ¿Es lo más acertado, para proteger este patrimonio, sustraer del territorio a los campesinos que llevan más de un siglo sembrando café? ¿O, en el mejor de los casos, entregándoles nuevamente estas tierras en calidad de usufructuarios, comodatarios, arrendatarios, etc.? ¿Qué pasaría con los demás valores asociados a la declaratoria del Paisaje Cultural Cafetero, relacionados con la interacción del hombre con el medio ambiente?

Aplicar el señalado criterio de la Corte a estos dos casos mencionados nos permite afirmar sin mayor duda el grave riesgo que ello comporta para dicho patrimonio, tratándose de un criterio que, reitero una vez más, está imbuido del mayor deseo de acertar en la defensa del patrimonio cultural, pero que produce exactamente el efecto contrario.

Finalmente el último aspecto que quisiera enunciar aquí es el relacionado con los recursos públicos que habría que comprometer para el cumplimiento de este criterio. No es posible calcular los inmensos recursos estatales de los cuales habría que disponer para la adquisición de 141.120 hectáreas del Paisaje Cultural Cafetero, o de los más de mil bienes de interés cultural declarados como tales que están en cabeza de particulares.

Como conclusión, es necesario señalar la necesidad de profundizar el análisis de esta problemática y considerar la viabilidad de tramitar un proyecto 
de ley que decante estos temas y refiera claramente el verdadero alcance de la interpretación de la Corte.

Si esto no fuera posible, sería necesario entonces pensar en una reforma de la norma constitucional que permita efectivamente la adecuada protección del patrimonio cultural.

De igual manera se haría sería preciso para resolver otro problema que corre paralelo a este. En efecto, existen muchos casos en los cuales el Estado termina adquiriendo por diversos medios (extinción de dominio u otros) bienes que tienen claramente una vocación comercial e industrial, la cual es completamente ajena a los propios cometidos del Estado, y cuya conservación en manos del mismo genera inmensos riesgos para el patrimonio cultural, teniendo en cuenta un elemento fundamental en todo este ejercicio como lo es su sostenibilidad económica. Implica entonces colocar al Estado en la condición irredimible de ejercer actividades comerciales y/o industriales, completamente ajenas a su accionar, y a lo que se ve sometido dada la naturaleza de inalienabilidad que las normas actuales consagran.

Invito entonces a acompañarnos en la profundización de este análisis y de las posibles soluciones que puedan existir para un adecuado mecanismo de protección del patrimonio cultural, como obligación y deber que tenemos todos los ciudadanos, tanto con las generaciones que nos antecedieron como con las que continuarán en la construcción de este país. 